\title{
Salivary Diagnostics for Managing Cellular Oxidative Stress
}

\author{
W. Jean Dodds* \\ Hemopet, 938 Stanford Street, Santa Monica, California, USA
}

*Corresponding author: W. Jean Dodds, Hemopet, 938 Stanford Street, Santa Monica, California, USA, E-mail: info@hemopet.org

\begin{tabular}{|c|c|}
\hline ARTICLE INFO & ABSTRACT \\
\hline Received: 幽 May 06, 2019 & Abbreviations: OS: Oxidative Stress; ROS: Reactive Oxygen Species; GST: Glutathione-5- \\
\hline Published: May 15, 2019 & $\begin{array}{l}\text { Transferases; GSH: Glutathione; TNF- } \alpha \text { : Tumor Necrosis Factor-Alpha; NK: Natural Killer; } \\
\text { IBD: Inflammatory Bowel Disease }\end{array}$ \\
\hline
\end{tabular}

Citation: W. Jean Dodds. Salivary Diagnostics for Managing Cellular Oxidative Stress. Biomed J Sci \& Tech Res 18(1)2019. BJSTR. MS.ID.003095.

\section{Mini Review}

In people and animals, cells are in homeostatic equilibrium when they are in oxidative balance, namely, when the cellular antioxidants (reducing agents) are balanced with the oxidants (oxidizing agents). However, when oxidant levels exceed antioxidants (termed cell redox), cells undergo oxidative stress (OS), which is the basic mechanism of all sickness and chronic disease [1-7]. Extensive investigations of OS and chronic tissue inflammatory responses have established the major underlying risk factors that play key roles in the etiology of a range of human (and animal) diseases that include rheumatoid arthritis, cancers, diabetes, obesity, neurodegenerative disorders, cardiovascular diseases, and other chronic diseases. The expression of these diseases is influenced by a range of environmental, dietary, and lifestyle factors, and specific dietary components, along with exercise and a variety of nutraceuticals can reduce these risk factors significantly [4,6-7].

Chronic inflammation from the increased free radical formation of OS, also called reactive oxygen species (ROS), occurs when tissues or organs receive inflammatory "mediator" messages that cause them to react as though the "trigger" or pathogen is still present. Rather than repairing themselves, these cells remain in an ongoing state of inflammation that can wax and wane life-long. Tissues thus become deficient in antioxidant mediators, such as malondialdehyde, glutathione, cysteine, ascorbic acid and other antioxidant vitamins, which is associated with a poor clinical outcome [6-7]. In healthy states, $25 \%$ of oxygen intake forms ROS, whereas this increases to $75 \%$ in unhealthy states and in aging [4]. When cells undergo damage, they release biomarker enzymes that lead to tissue inflammation, infections, obesity and even cancers. Biomarkers of clinical relevance in people and pets include isoprostane, Nrf-2, microRNA, and others [6,7]. When elevated, the presence of high levels of these biomarkers can be addressed with diet and supplement changes to promote beneficial anti-oxidant effects [4,6,7] [cellbiomarkers.org]. These assays are repeated periodically to assess the response and adjust nutritional and nutraceutical therapy, as needed. Management of OS has focused on the development of functional foods, e.g. those containing natural Nrf-2 activators. These include such antioxidant ingredients as: turmeric (Curcuma longa); and its relative, ginger (Zingiber officiale); chili peppers (Capsicum annuum); green tea (Camellia sinensis, which contains tannins and polyphenol catechins, and other teas); soybeans (Glycine max); tomatoes (Solanum lycopersicum, rich in lycopenes); grapes (not for pets); honey (not for infants or very young animals); cranberries (Vaccinium macrocarpon, contains pro-anthocyanidins); licorice (Glycyrrhiza glabra); garlic (Allium sativum, in moderation for pets); milk thistle (Silybum marianum);cabbages and broccoli (Brassica oleracea var. capitata and var. italia) $[4,6,7]$. 


\section{Some Primary Oxidative Stress BioMarkers [6,7]}

Isoprostanes: are a series of prostaglandin-like compounds produced by peroxidation of arachidonic acid. This process is catalyzed by ROS, and they are considered the "gold standard" test for quantifying lipid peroxidation/OS in vivo in humans and animals.

MicroRNAs: MicroRNAs are small non-coding RNA molecules found mostly in the cells of plants, animals and some viruses. They functions in RNA silencing and post-transcriptional regulation of gene expression. The function of microRNAs is in gene regulation.

Glutathione-5-Transferases (GST): previously called ligandins, belong to a superfamily of metabolic isozymes best known for their ability to catalyze conjugation of the reduced form of glutathione (GSH) to foreign substrates for the purpose of detoxification. They are found in plants, animals, fungi, and some bacteria. GSH prevents damage to cells by ROS, peroxides, lipid peroxides, and heavy metals, and plays an important role in cell signaling. Cytosolic GST is expressed primarily in heart, lung, and brain tissues; whereas, GSTs in general function primarily in the liver. High levels of GST are associated with resistance to the apoptosis (cell death) induced by a range of substances, including chemotherapeutic agents. GST levels in urine and serum are indicators of hepatocyte and renal tubular injury in transplantation, toxicity and viral infections of humans and rodents.

Malondialdehyde: A reactive aldehyde, occurs naturally as a biomarker for OS and is formed when ROS degrade polyunsaturated lipids. Malondialdehyde is potentially mutagenic, and has been found in heated edible oils such as sunflower and palm oils. Corneas of human patients suffering from keratoconus and bullous keratopathy have increased levels of malondialdehyde, and this aldehyde also can be found in tissue sections of joints from human patients with osteoarthritis.

Tumor Necrosis Factor-Alpha (TNF- $\alpha$ ): also called cachexin or cachectin, is a cell signaling protein involved in systemic inflammation and is one of the cytokines that make up the acute phase inflammatory response. It is produced chiefly by activated macrophages, although it can be produced by many other cell types such as CD4+ lymphocytes, natural killer (NK) cells, neutrophils, mast cells, eosinophils, and even neurons.

TNF is an endogenous pyrogen that can induce fever, apoptotic cell death, cachexia, inflammation, inhibit tumorigenesis and viral replication, and respond to sepsis via interleukin IL-1 and IL-6 producing cells. Dysregulation of TNF production has been implicated in a variety of human diseases such as Alzheimer's disease, cancer, depression, psoriasis and inflammatory bowel disease (IBD).

Other Biomarker Enzymes Include: Sorbitol Dehydrogenase, a cytosolic enzyme that converts sorbitol, the sugar alcohol form of glucose, into fructose; and 5' Nucleotidase, which catalyzes the phosphorolytic cleavage of $5^{\prime}$ nucleotides, and is considered a maturation marker for T- and B-cells.

\section{Measuring Biomarker Enzymes of Oxidative Stress $[1,4,6,7]$ Cellbiomarkers.org]}

Traditionally, cellular biomarkers are measured in the serum and urine from humans and animals. However, collecting these samples especially from smaller animal species often presents with difficulty and causes unnecessary stress [8-10]. Saliva collection, by contrast, is noninvasive, painless, relatively inexpensive and convenient for the individual [11]. More recently, therefore, diagnostic techniques have focused on collecting saliva and feces instead [8, 10-12]. Like food sensitivity testing, salivary testing can reveal the latent or pre-clinical form of developing OS. [11] cellbomarkers.org]. The levels of salivary biolipids, like isoprostane, also are predicted to reflect the general mucosal immune response and can be induced in people and animals without parallel antibodies being detected in serum $[6,7,10]$.

\section{References}

1. Hidalgo M, F Amant, AV Biankin, E Budinska, AT Byrne, et al. (2014) Patient-derived xenograft models: an emerging platform for translational cancer research. Cancer Discov 4(9): 998-1013.

2. Siolas D, GJ Hannon (2013) Patient-Derived Tumor Xenografts: Transforming Clinical Samples into Mouse Models. Cancer Research 73(17): 5315-5319.

3. Liu H, MR Patel, JA Prescher, A Patsialou, D Qian, et al. (2010) Cancer stem cells from human breast tumors are involved in spontaneous metastases in orthotopic mouse models. Proc Natl Acad Sci U S A 107(42): 1811518120.

4. Williams ES, V Rodriguez Bravo, U Chippada Venkata J De Ia Iglesia Vicente, Y Gong, et al. (2015) Generation of Prostate Cancer Patient Derived Xenograft Models from Circulating Tumor Cells. J Vis Exp 105: 53182.

5. Hodgkinson CL, CJ Morrow, Y Li, RL Metcalf, DG Rothwell, et al. (2014) Tumorigenicity and genetic profiling of circulating tumor cells in smallcell lung cancer. Nat Med 20(8): 897-903.

6. Liu X, R Taftaf, M Kawaguchi, YF Chang, W Chen, et al. (2019) Homophilic CD44 Interactions Mediate Tumor Cell Aggregation and Polyclonal Metastasis in Patient-Derived Breast Cancer Models. Cancer Discov 9(1): 96-113.

7. Aceto N, A Bardia, DT Miyamoto, MC Donaldson, BS Wittner, et al. (2014) Circulating tumor cell clusters are oligoclonal precursors of breast cancer metastasis. Cell 158(5): 1110-1122.

8. Chen K, S Ahmed, O Adeyi, JE Dick, A Ghanekar (2012) Human solid tumor xenografts in immunodeficient mice are vulnerable to lymphomagenesis associated with Epstein-Barr virus. PLoS One 7(6): e39294.

9. Bondarenko G, A Ugolkov, S Rohan, P Kulesza, O Dubrovskyi, et al. (2015) Patient-Derived Tumor Xenografts Are Susceptible to Formation of Human Lymphocytic Tumors. Neoplasia 17(9): 735-741.

10. Taurozzi AJ, R Beekharry, M Wantoch, MC Labarthe, HF Walker, et al. (2017) Spontaneous development of Epstein-Barr Virus associated human lymphomas in a prostate cancer xenograft program. PLoS One 12: e0188228. 
ISSN: 2574-1241

DOI: 10.26717/BJSTR.2019.18.003095

W. Jean Dodds. Biomed J Sci \& Tech Res

(c) (P) This work is licensed under Creative Commons Attribution 4.0 License

Submission Link: https://biomedres.us/submit-manuscript.php

$\begin{array}{ll}\text { BIOMEDICAL } & \text { Assets of Publishing with us } \\ \text { RESEARCHES } & \text { - Global archiving of articles } \\ & \text { - Immediate, unrestricted online access } \\ & \text { - Rigorous Peer Review Process } \\ \end{array}$

